\title{
Advertising insert as a special genre of advertising text
}

\section{S. N. Prokhorova ${ }^{1}$}

1P. G. Demidov Yaroslavl State University, 14 Sovetskaya str., Yaroslavl 150003, Russian Federation

DOI: $10.18255 / 2412-6519-2020-4-388-397$

Research Article

Full text in Russian

The article deals with the translation of feminine film titles on the example of English filmonyms of the last decade. The article is aimed at the study of the filmonyms' translation in the Russian film discourse, which leaves its specific imprint on the translator's decisions. The paper treats the translation of feminine-marked filmonyms as a topical problem of the linguistics of gender and the theory of translation - the study of the means of translation of feature film titles from English to Russian from the point if view of gender-marked translators' slant. The application of the method of typological synchronous comparison allows to compare translation from the point of view of the feminine-masculine balance and the presence of feminine markers. The comparison is based on the thesis of adaptation and deformation of the source English film title. If the adaptation focuses on the convergence of the translation to the source culture and its specifics and is oriented on the mutrual cultural dialogue, then the deformation, on the contrary, prioritises the peculiarities of the accepting culture. The author of the article proves the thesis that in many cases the translation is not tolerant, the point of view of the translator affects the translation and therefore women are presented as nervous, obese, mentally different and emotionally unstable.

Keywords: filmonym; localization; gender; translation; transcreation; appropriation; domestication

\section{INFORMATION ABOUT THE AUTHORS}

$$
\begin{array}{l|l}
\text { Prokhorova, Svetlana N. } & \begin{array}{l}
\text { E-mail: svnp@mail.ru } \\
\text { Cand. Sc. (Culturology), associate Professor }
\end{array}
\end{array}
$$

For citation: Prokhorova S. N. Advertising insert as a special genre of advertising text // Social'nye i gumanitarnye znanija. 2020. Vol. 6, No 4. P. 388-397. (in Russ.) 


\title{
Рекламный вкладыш как особый жанр рекламного текста
}

\author{
С. Н. Прохорова ${ }^{1}$
}

1Ярославский государственный университет им. П.Г. Демидова, ул. Советская, 14, Ярославль, 150003, Российская Федерация

DOI: $10.18255 / 2412-6519-2020-4-388-397$

УДК 1751

Научная статья

Полный текст на русском языке

В статье рассматривается рекламный вкладыш как особый жанровый феномен. Представлено определение рекламного вкладыша, анализируются тексты печатных рекламных вкладышей по комплексной модели описания, выделены жанровые особенности вкладышей по следующим конститутивным признакам: коммуникационная цель, образ автора, образ адресата, образ прошлого, образ будущего, тип диктумного (событийного) содержания, языковое воплощение. Автор считает, что вкладыш является текстом особого жанра, основные задачи которого - подтвердить правильный выбор торговой марки и продукта; предоставить инструкцию по эксплуатации товара, дать рекомендации по уходу за купленной вещью; получить обратную связь от покупателя; поддержать отношения с покупателем; в конечном итоге сформировать лояльность клиента и обеспечить повторные покупки. Проведенное исследование показало, что рекламный вкладыш представляет собой особый текстовый феномен, схожий с текстами рекламных жанров, но отличающийся такими жанрообразующими признаками, как цель, образ прошлого, образ будущего. Результаты исследования позволяют утверждать, что на сегодняшний день не сложилось единой модели текста рекламного вкладыша: производители ставят перед рекламным вкладышем разные задачи и используют разные стратегии реализации поставленных задач. Многие конститутивные признаки проанализированных рекламных вкладышей схожи, что позволяет выделить эту категорию сообщений в самостоятельный жанр.

ключевые слова: текст; вкладыш; рекламный текст; рекламный вкладыш; жанр; маркетинговые коммуникации; рекламная коммуникация; рекламный дискурс

\section{ИНФОРМАЦИЯ ОБ АВТОРАХ}

Прохорова, Светлана Николаевна

Email: svnp@mail.ru

Кандидат культурологии, доцент кафедры теории и

практики коммуникации

Для цитирования: Прохорова С. Н. Рекламный вкладыш как особый жанр рекламного текста // Социальные и гуманитарные знания. 2020. Том 6, № 4. С. 388-397.

(C) Прохорова С. Н., 2020

Статья открытого доступа под лицензией СС BY (https://creativecommons.org/licenses/by/4.0/) 
Обеспечение коммуникации с потребителями стало необходимым условием успешного функционирования производителей товаров и услуг в информационную эпоху. Исторически сложились различные формы рекламных сообщений, обеспечивающих эффективную маркетинговую коммуникацию производителя (или продавца) с потребителем.

Феномен рекламного текста достаточно изучен и описан. Л. Г. Фещенко определяет рекламный текст как «коммуникативную единицу, функционирующую в сфере маркетинговой коммуникации для неличного оплаченного продвижения товара, услуги, лица или субъекта, идеи, социальной ценности, имеющую в структуре формальный признак - сигнализирование о характере информации, обязательное по закону о рекламе (презентацию), один или несколько компонентов бренда и/или рекламные реквизиты и отличающуюся равной значимостью вербально и невербально выраженного смысла» [1, с. 27]. Любовь Георгиевна Фещенко, предлагая рабочее определение, берет во внимание определение феномена рекламы, приведенное в Федеральном законе о рекламе РФ от 1995 года, а также понимание рекламы, принятое в теории маркетинга.

А. Д. Кривоносов, определяя рекламный текст, также учитывает определение рекламы в законе РФ, исходит из типа информации, содержащейся в тексте: «рекламным можно признать текст, который:

1) содержит информацию о физическом или юридическом лице, товарах, идеях или начинаниях;

2) предназначен для неопределенного круга лиц;

3) призван формировать или поддерживать интерес к физическому, юридическому лицу, товарам, идеям, начинаниям;

4) способствует реализации товаров, идей, начинаний» [2, с. 8].

К рекламным текстам принято относить «продающие тексты»: те, что продвигают товар или услугу. Мы встречаемся с рекламными сообщениями постоянно: на улице, в общественном транспорте, в лифте, в торговых центрах, в интернете.

Достаточно распространены в наше время такие формы коммуникации с потребителем, как «рекламные вкладыши» - сообщения на бумажном носителе, которые вкладываются в упаковку с товаром. Подобного рода явление возникло не сегодня, о чем свидетельствуют примеры в литературе [3].

Многие жанры печатной рекламы достаточно изучены и подробно описаны: информационный лист, информационное письмо, листовка, буклет, проспект, каталог, плакат и так далее [4, с. 117]. В специальной литературе встречаются также упоминания о рекламном вкладыше и определения этого явления: «Вкладыш - небольшой рекламный листок, в котором описываются преимущества данного товара. Их обычно вкладывают в упаковку с тем, чтобы побуждать покупателей к повторным покупкам» [5, с. 411]. Однако, несмотря на распространенность такого рода рекламных форм, мы не встретили описаний рекламного вкладыша в учебной и научной литературе: жанровые особенности рекламных вкладышей, способы и средства оформления обращений к покупателю до последнего времени не были предметом изучения в теории рекламного дискурса.

Традиционная модель процесса покупки товара включает несколько стадий: осознание проблемы, поиск информации, оценка вариантов, решение о покупке, реакция на покупку [6, с. 160]. Потенциальный покупатель последовательно проходит подготовительные стадии, прежде чем принимает решение о покупке товара, после покупки товара следует стадия реакции на покупку (рис. 1). 
Рисунок 1. Стадии процесса покупки товара

С рекламным вкладышем покупатель встречается, когда товар уже куплен, на стадии «реакция на покупку». Следовательно, задачи такого типа сообщений отличаются от задач традиционных рекламных текстов: привлечь внимание к товару, заинтересовать, побудить потребителя сделать покупку.

Для выявления жанровых особенностей рекламного вкладыша было проанализировано 52 текста вкладышей, отобранных методом случайной выборки в период с сентября 2013 по май 2015 года. Отбирались сообщения, вложенные в упаковку с товаром и в пакет с покупкой.

Цель исследования - проанализировать жанровые особенности рекламных вкладышей. Объектом исследования стали тексты печатных рекламных вкладышей, вложенных в упаковку с товаром, а предметом исследования - жанровые особенности рекламных вкладышей.

Собранный материал распределился по товарным категориям следующим образом:

1. Косметические и парфюмерные средства - 22 шт.

2. Одежда, обувь и аксессуары - 14 шт.

3. Ювелирные украшения и бижутерия - 6 шт.

4. Продукты питания и напитки - 7 шт.

5. Лекарственные препараты - 1 шт.

6. Товары для творчества - 2 шт.

Мы выделили жанровые особенности собранных текстов по предложенной T. В. Шмелёвой комплексной модели описания так называемого «паспорта жанра». Напомним, что исследователь предлагает изучать жанровые модели, анализируя поэтапно семь конститутивных признаков [7, с. 92]:

1. Коммуникационная цель.

2. Образ автора.

3. Образ адресата.

4. Образ прошлого.

5. Образ будущего.

6. Тип диктумного (событийного) содержания.

7. Языковое воплощение.

В данной статье ограничимся описанием шести первых признаков, седьмой признак (языковое воплощение) будет затронут при описании формы выражения первых шести конститутивных признаков. Рассмотрим рекламные вкладыши поэтапно по предложенным жанрообразующим признакам.

1. Коммуникационная цель. Первая жанровая особенность рассматриваемого типа сообщений заключается в особой коммуникационной цели: создать у покупателя уверенность в правильном выборе компании и продукта, предоставить инструкцию по эксплуатации товара, дать рекомендации по уходу за купленной вещью, чтобы она служила долго; получить обратную связь от покупателя; поддержать от- 
ношения с покупателем; в конечном итоге обеспечить лояльность клиента и повторные покупки. Эти цели не всегда выражены открыто в тексте, а угадываются за содержанием и формой отдельных структурных элементов.

2. Образ автора. В большинстве рассматриваемых текстов образ автора скрыт: такая особенность характерна для рекламных текстов в целом. Внимание в текстах акцентируется на самом продукте:

«Крем питает и увлажняет»,

а также на производителе:

«Косметика Natura Siberica рассчитана на думающих потребителей, которым небезразлично собственное здоровье».

Но в некоторых случаях образ автора выражен грамматически местоимением множественного числа «мы»:

«Для большей эффективности средств и повышения результативности, мы рекомендуем использовать средство вместе с...» (перечисляются другие продукты серии);

«Мы ценим Вашу лояльность к нашей торговой марке»;

«... Мы используем натуральные производные сахаров и аминокислот»;

«Мы позволяем Вам оставаться в гармонии с собой и чувствовать себя великолепно»;

«... нашей задачей, прежде всего, было использовать всю накопленную многими поколениями мудрость жителей Сибири...».

Есть несколько примеров, где автор персонифицирован в лице коллектива или руководителя компании:

«Нам всегда было очень важно Ваше мнение... С уважением, коллектив компании «Первое решение».

«...И не сомневаемся, что льняная каша станет для Вас таким же любимым и необходимым продуктом, каким уже является для нас, наших детей и родителей. Будьте здоровы! Коллектив 000 «ВиП Продукт».

Особое место среди отобранных примеров занимают рекламные вкладыши, обнаруженные нами в упаковке зубной пасты «Сплат»: они созданы в форме писем директора компании к покупателям. В каждом письме затрагивается социально значимая проблема, письма носят личностный доверительный характер и заканчиваются этикетной формулой, которой обычно завершается письмо, и личной подписью:

«С уважением, генеральный директор Евгений Демин и команда SPLAT».

Эти обращения выполнены в форме эпистолярного жанра, а задачи их близки к задачам PR-коммуникации: сформировать и поддержать лояльность покупателей, доверительное отношение к компании.

3. Образ адресата. Адресат рекламного вкладыша - покупатель, пользователь продукции. В рекламной коммуникации распространен термин «целевая аудитория» - «определенный в ходе выработки рекламной стратегии круг людей, которые по своим характеристикам наиболее склонны к покупке нашего брэнда» [8, с. 25]. Сложность составления текстов массовой коммуникации состоит в том, что, с одной стороны, адресат сообщения не является конкретным лицом, а с другой стороны, важно, чтобы сообщение было воспринято и понято каждым читателем лично.

Ирина Георгиевна Морозова отмечает, что указание на целевую аудиторию может иметь как прямую (номинативную) форму, так и описательную (контекстуальную) [6, с. 26]. Прямой способ указания на адресата - это называние его в тексте: 
«Серия «Люкс» включает в себя продукцию улучшенного качества для учащихся художественных школ...»;

«Косметика Natura Siberica рассчитана на думающих потребителей, которым небезразлично собственное здоровье».

В первом случае целевая аудитория - учащиеся художественных школ названа по увлечению, роду занятий. Во втором случае - категория людей, которые заботятся о своем здоровье. Такого рода выражение образа адресата - еще и своеобразный комплимент покупателю: продукция предназначена для учащихся художественных школ, будущих профессионалов, продукция улучшенного качества, сравнима с профессиональными материалами для художников. Ребенок может и не учиться в художественной школе, но пользоваться красками серии «Люкс». А покупателю косметики Natura Siberica будет лестно прочитать, что она предназначена для «думающих потребителей, которым небезразлично собственное здоровье».

Но прямое указание на адресата встречается довольно редко в рекламных вкладышах: лишь в одном примере мы нашли обращение к покупателю:

«Дорогой покупатель! Если Вы держите в руках эту книжечку...».

Часто адресат сообщения представлен в тексте грамматически с помощью местоимения второго лица, глагола повелительного наклонения, который имеет только форму второго лица:

«Благодарим Вас за покупку чая «Гармония природы».

«Вы сможете управлять своими желаниями, мечтами и окружающими вас явлениями...».

«Попробуйте коллекцию насыпных чаев «Гармония природы!».

«Вы сможете управлять.... 31 декабря приготовьте....».

Все эти примеры не содержат конкретного образа покупателя, в текстах лишь указывается адресат, содержится вежливое обращение к нему, в то же время не называются какие-либо признаки покупателя: возраст, гендерные характеристики, род занятий.

Таким образом, можем сделать вывод, что образ автора в рекламных вкладышах чаще всего обобщен и не выражен точно в тексте. Эта особенность характерна для текстов массовой коммуникации в целом.

4. Образ прошлого. В текстах рекламных вкладышей образ прошлого выражен контекстуально: если человек читает вкладыш, который был вложен в упаковку товара, значит, он купил или получил в подарок товар, стал владельцем этого товара. В отдельных случаях факт покупки и благодарность за покупку находит выражение в тексте:

«Thank you for your purchase of UGG Australia footwear. Your shoes are made from the finest materials available and will provide you with all of the comfort and luxury you've can to expect from UGG Australia» (Благодарим вас за покупку обуви UGG Australia. Ваша обувь сделана из лучших материалов и предоставит Вам весь комфорт и роскошь, которые вы можете ожидать от UGG Australia).

«Мы ценим лояльность к нашей торговой марке!»

«Оливин мягкого зеленого цвета и черный обсидиан - это кристаллические полудрагоценные камни вулканического происхождения, которые можно встретить на Канарских островах. Начиная с каменного века обсидиан использовался в качестве оружия и орудия труда, а в Древнем Египте его применяли как религиозное и магическое украшение». 
В приведенных примерах подчеркивается высокое качество продукции, материалов, из которых она изготовлена, а также выражается признательность покупателю за выбор именно этой продукции.

5. Образ будущего. Категория «образ прошлого» перетекает в категорию «образ будущего». В этой категории находят выражение задачи коммуникации. Производитель ценит, что покупатель выбрал его товар, и спешит убедить его в том, что выбор сделан правильно, куплен товар высокого качества, впереди приятные моменты пользования продуктом:

«Дорогой покупатель! Если Вы держите в руках эту книжечку, значит, Вы уже близки к тому, чтобы совершить маленькое открытие, так же, как в свое время были и мы - производители этого нового на российском рынке продукта».

«Shafer - это компания с 30-летним опытом работы в области изготовления и продажи ювелирных изделий. Мы гарантируем, что все наши изделия содержат подлинный оливин-передот и изготовлены из золота 18 карат и серебра 925 пробы. Коллекция украшений с драгоценными камнями оригинального дизайна делает наши ювелирные изделия особым и эксклюзивным подарком».

Подтверждение качества:

«Что нового Вы найдете для себя в этом продукте? 1. На 25 \% больше экстрактов сибирских трав. 2. В два раза увеличено содержание D пантенола и алантоина, которые способствуют омоложению и регенерации кожи...».

Подтверждение качества товара нередко выражено во вкладышах с помощью гарантийного сертификата, сертификата качества, перечисления наград товара, размещения отзывов потребителей.

На рекламном вкладыше часто размещают фотографии и описание других товаров производителя: при покупке чая покупатель находит в упаковке вкладыш с описанием других сортов чая того же производителя; при покупке косметики - другие средства по уходу за кожей этой же серии, в коробку с серебряным кольцом марки Shafer вложен вкладыш с фотографиями ювелирных изделий этого бренда: «Мы с гордостью представляем вам нашу коллекцию ювелирных изделий из серебра и золота с оливин-передотом и обсидианом».

В коробку с обувью Ессо вложен вкладыш с инструкцией по эксплуатации, а также фотографиями и описанием продукции по уходу за обувью этой же марки, телефоном информационной линии и адресом сайта. Такого рода информация, как и в предыдущем примере, - приглашение к последующей покупке. Желаемый образ будущего - повторные покупки товара, а также покупки других товаров этой торговой марки.

Желаемое в будущем действие покупателя часто напрямую сформулировано с помощью глаголов повелительного наклонения:

«Попробуйте зрелый сыр ДЖЮГАС® с капелькой натурального меда - будете приятно удивлены сочетанием...».

«Запишите каждое из трех желаний и опустите их в бутылку».

«Узнайте больше о наших принципах и кампаниях на сайте: ...».

«Обменяйте купон на миниатюру сыворотки Super Aqua-serum (3 мл) с 1 апреля 2014 года в магазинах ИЛЬ ДЕ БОТЕ».

Покупателю предлагается попробовать сыр с медом, причем в этом же вкладыше представлена и коллекция сыра в сувенирной подарочной упаковке, таким образом контекстуально предлагается купить сыр в подарок. 
Производитель хочет получить обратную связь от покупателя, отзыв о качестве товара: с этой целью в рекламный листок добавляется анкета обратной связи либо предлагается зайти на сайт и оставить свой отзыв там, просьба присылать замечания по обслуживанию, предложение делиться своими рецептами с обещанием подарка за лучшие рецепты. Также встретился купон на скидку на последующие покупки, что также является приглашение сделать повторную покупку.

6. Тип диктумного (событийного) содержания. Анализ содержательной составляющей текстов показал, что больше всего в текстах вкладышей встречается информация с описанием уникальных свойств товара (20 примеров), историей и философией компании-производителя (15 примеров), демонстрацией и описанием других товаров этой фирмы (12 примеров). Реже - благодарность за покупку товара компании, рекомендации по уходу за товаром (по восемь примеров), инструкция по эксплуатации товара, гарантийный сертификат, полезная информация о товарах подобной категории, письма и отзывы потребителей, рецепты по приготовлению продукта (по три примера).

7. Языковое воплощение. Большинство примеров содержит иллюстрации, фотографии, графическую составляющую: это помогает привлечь внимание, продемонстрировать высокое качество продукта, создать привлекательный образ продукта и бренда. Использование заголовков, подзаголовков, «врезок» позволяет акцентировать внимание читателя на самых важных семантических составляющих текста.

Проведенное исследование показало, что рекламный вкладыш представляет собой особый текстовый феномен, схожий с текстами рекламных жанров, но отличающийся такими жанрообразующими признаками, как цель, образ прошлого, образ будущего. Результаты исследования показали, что на сегодняшний день не сложилось единой модели текста рекламного вкладыша: производители ставят разные задачи и используют разные стратегии реализации задач. Но многие конститутивные признаки проанализированных рекламных вкладышей схожи, что позволяет выделить эту категорию сообщений в самостоятельный жанр.

\section{Ссылки / References}

1. Фещенко Л. Г. Структура рекламного текста: учебно-практическое пособие. СПб.: Петербургский институт печати, 2003. 232 с.

2. Кривоносов А. Д., Шевченко А. С. Копирайтинг и спичрайтинг: учебное пособие. СПб.: СПбГЭУ, 2018. 66 с.

3. Глинтерник Э. М. Реклама в России XVIII - первой половины XX века. М.: Аврора, 2007. $360 \mathrm{c.}$

4. Рекламная деятельность: учебник для студентов высших учебных заведений / Ф. Г. Панкратов, Ю. К. Баженов, Т. К. Серегина, В. Г. Шахурин. М.: Дашков и К을 2003. 364 с.

5. Беляев В. И. Маркетинг: основы теории и практики: учебник. М.: Кнорус, 2005. 672 с.

6. Котлер Ф. Основы маркетинга. Краткий курс. М.: Вильяме, 2007. 656 с.

7. Шмелева Т. В. Модель речевого жанра // Жанры речи. Саратовский национальный исследовательский государственный университет им. Н. Г. Чернышевского. 1997. № 1. С. 88-98.

8. Морозова И. Слагая слоганы. М.: РИП-холдинг, 2001.172 с. 